\title{
Response and interventions into harmful sexual behaviour in schools
}

Internationally young people report experiencing sexual abuse and violence within schools. Developments within the field of adolescent sexual harm are increasingly recognising the need for ecological approaches to harm. Yet, to date, interventions with young people displaying harmful sexual behaviours have prioritised individual behaviours and characteristics over place-based interventions.

This article presents empirical evidence from a mixed-methods study aimed at understanding the enablers and barriers to preventing and responding to harmful sexual behaviour in schools. Research was carried out in seven schools and four multi-agency partnerships in England, UK. Using evidence from focus groups, observations, case reviews and policy analysis the article outlines nine components that enable, or are barriers to, effective responses and interventions into harmful sexual behaviour in schools. The paper concludes that responses and interventions into harmful sexual behaviour must move beyond responding to individual behaviours to intervening within factors within schools themselves.

Keywords: harmful sexual behaviour, schools, adolescents, contextual safeguarding, whole-school, sexual abuse

\section{Introduction}

Young people experience and display harmful sexual behaviours (HSB) in schools internationally. In the US, Turner et al. (2011) revealed $72 \%$ of sexual harassment, $25 \%$ of sexual assaults and $17.5 \%$ of rape experienced by adolescents occurred within school as opposed to elsewhere. In a similar study in the US, Young, Grey, and Boyd (2009) found peer-on-peer sexual assault most often occurred on school grounds. In the UK, Girlguiding (2017) found $64 \%$ of girls aged 13-21 had experienced sexual harassment in school or college in the last year. While studies into sexual violence in schools predominantly focus on North America and Europe, evidence suggests that sexual harassment and abuse in schools is a problem for young people internationally, including in South America, Asia and Africa (Jones, Moore, Villar-Marquez, \& Broadbent, 2008). 
The occurrence of sexual abuse and violence in schools is not coincidental. Research suggests there are characteristics about schools themselves that facilitate different forms of harm in school, such as sexual harassment, bullying and violence. (Cowie, 2011; C. Firmin, 2017). These may relate to a range of factors from the physical layout, student body or staff training and conduct. For example, the inability of staff to respond to harm in schools can be seen to facilitate abuse (Barnes et al., 2012), or reduce the likelihood of students seeking help (Aceves, Hinshaw, Mendoza-Denton, \& Page-Gould, 2010). Exposure to unsafe school environments impacts student perceptions of safety informing how they navigate schools, in some cases increasing weapon carrying within school (Goldstein, Young, \& Boyd, 2008). In relation to bullying, the physical landscape, makeup of the student body, staff development and absence of peer support networks have been identified as factors conducive to harm in schools (Espelage \& Swearer, 2004), as well as a range of factors that can protect young people from harm (Nelson, Burns, Kendall, \& Schonert-Reichl, 2017). Research into sexual harm in schools has shown how education can reinforce, rather than challenge, harmful sexist cultures (Dobson \& Ringrose, 2016) by normalising hegemonic gender regimes in schools (Benton, 2014; Swain, 2006).

Sexual abuse is traumatising for anyone, wherever the location. But when sexual abuse happens within schools, in places meant to keep young people safe, the impacts have a lasting legacy. These consequences include poor mental health (Fineran, 2002), lowered selfesteem and confidence to participate in class by girls, falling grades and attendance (Duffy, Wareham, \& Walsh, 2004; Girlguiding, 2017), and self-harm, anxiety and depression (House of Commons, 2016). Schools play a crucial role in responding to sexual harm and preventing abuse. Yet, to date, research and practice developments into HSB have largely focussed on individual young people, through individual interventions, rather than the factors within schools themselves that may create environments conducive of harm. 
This paper presents a contextual approach to HSB by exploring response and interventions into sexual abuse and violence in schools. Using a Contextual Safeguarding framework (Firmin, 2017) factors within schools themselves - as opposed to risks and vulnerabilities within people - and the relationship between the school and multi-agency partners are explored. Using this ecological perspective, research carried out in schools and multi-agency partnerships in England, including focus groups, observations and case reviews, is analysed to reflect upon elements of a contextual approach to response and intervention. Building upon international literature on HSB interventions with people and whole-school preventative approaches to sexual harm, I question the predominant focus of HSB interventions with people to argue for greater acknowledgement and understanding of components within places that may contribute to harm.

\section{Definition}

This article uses Hackett's (2014) definition of HSB. Hackett (2014 online) defines HSB as the 'Sexual behaviours expressed by children and young people under the age of 18 years old that are developmentally inappropriate, may be harmful towards self or others, or be abusive towards another child, young person or adult' (Hackett, 2014). HSB encompasses a range of behaviours, from sexual name-calling and harassment, online sexual bullying and sexual image sharing to unwanted touching and rape. This article considers the relationship between the school context, multi-agency partners and response and interventions into HSB in schools. Response is the reaction to an incident, and intervention is the actions taken to improve the situation. I begin by considering current interventions into HSB.

\section{Interventions into HSB}

In the UK, the prevailing statutory guidance to schools for responding to HSB advises making a referral to social care or the police, often initiating an individual response to the 
young person involved. As such, interventions into HSB predominately focus on targeting individual young people's behaviour, rather than the environments where harm occurs. In some cases young people displaying HSB are responded to through criminal justice responses - as opposed to welfare (C. Smith et al., 2014). And while there is some non-statutory advice (Department for Education, 2018b), limited guidance exists for schools on what to do beyond a referral. Responding to HSB requires holistic assessments and interventions rooted in welfare approaches (Pratt, 2013; Scott \& Telford, 2006). These need to be supported by clear policy and guidance to ensure consistent responses, and HSB interventions that recognise young people's needs and the influence of the social context of schools (Masson \& Hackett, 2003). In the following I review literature related to interventions into HSB, firstly with people, and secondly places.

\section{Interventions with people}

Predominantly, interventions used to target HSB have focussed on people, their individual behaviours and risk avoidance strategies (Caldwell, 2002). In the US, the prevailing programme used to 'treat' HSB is cognitive-behavioural therapy (CBT) (McGrath, Cumming, Burchard, Zeoli, \& Ellerby, 2009). In his review of HSB interventions, Hackett (2014) outlines several effective psycho-educational CBT interventions for pre-adolescent children with sexual behaviour problems. While these may be appropriate for children, Hackett notes that programmes targeted at older young people are instead often adapted models offered to adult sex offenders and predominantly focus on factors associated with individual people (Dopp, Borduin, Rothman, \& Letourneau, 2017). This can include, conditioning to alter arousal patterns, increasing empathy for victims, reducing denial or providing education (Borduin \& Schaeffer, 2002). In the whole these approaches have been typified by risk avoidance strategies, for example - despite evidence to the contrary (Caldwell, 2002) -those 
aimed at reducing the risk of future sex offences. For example, placing young people on public registers or excluding them from mainstream education. Yet critics suggest distinct specialist work, focussed on restrictive treatment measures, can stigmatise and exclude young people (Chaffin, 2008). Furthermore, they do little to alter the environments where harm occurs.

Young people displaying HSB share many similar risk factors to other young people who commit non-sexual offences (Ronis \& Borduin, 2013). As such, researchers and clinicians are developing alternative evidence-based strategies to working with young people. For example, environmental approaches to sexual abuse that consider the young person's social ecology, by recognising the influence of environments to human behaviour (RaymentMcHugh, Smallbone, \& Tilley, 2015) . By acknowledging and understanding the social contexts young people spend time in, practitioners can recognise the influence of social norms and rules to behaviour, and consider steps to disrupt or challenge these if they have a negative influence.

Multi-systemic therapy (MST) is an approach which, when tailored for young people displaying HSB, provides a family and community based approach, equipping caregivers with tools to address HSB (Henggeler, Schoenwald, Borduin, Rowland, \& Cunningham, 2009). Instead of targeting interventions with young people displaying HSB on behavioural or cognitive issues, MST appreciates young people's ecology (Borduin \& Schaeffer, 2002). Therapists then use several interventions focused on both individual and ecological factors (Letourneau \& Borduin, 2008). Within families, this might include removing barriers to effective parenting or enhancing communication between family members. Within peer groups, this can involve encouraging pro-social skills and developing friendships. At the school level, the young person and their family may be supported to promote academic 
achievement (Dopp et al., 2017). MST offers a comprehensive intervention for targeting the multiple individual aspects of young people's HSB while recognising young people's social ecology (Borduin, Schaeffer, \& Heiblum, 2009). Evaluations have evidenced its effectiveness at reducing young people's sexual and non-sexual offending (Letourneau et al., 2009).

The Good Lives Model is an offender rehabilitation programme that addresses the holistic nature of sexual harm (Ward \& Brown, 2004). In this model, practitioners support young people to identify and map their needs and find ways to achieve 'goods'. For example, life, knowledge, pleasure, creativity and community (The Good Lives Model, 2018). Rather than focus on the risks young people present, therapists work with young people to consider their needs and develop a plan accounting for internal and external conditions to help the young person to realise this life. This might include promoting positive relationships, enjoyable leisure activities or through rewarding work, while supporting the young person to challenge problematic views and outlooks (Ward, Vess, Collie, \& Gannon, 2006). Unlike traditional risk aversion models, in the Good Lives Model, risks are viewed as barriers that prevent young people meeting their needs.

Proponents of holistic and developmental approaches to HSB advocate for the need for interventions to understand the broader systemic contexts of young people's lives (Hackett, 2014). While the models highlighted here recognise the significance of young people's ecology to their sexual behaviours, for example the community and their relationships with peers, others have noted these interventions remain targeted on the individual without intervening within the contexts where harm occurs (Smallbone, RaymentMchugh, \& Smith, 2013). For example, they may focus on increasing attendance at school rather than changing the school culture itself, if it is seen to have fostered harmful gendered 
norms. However, some researchers in the field of sexual violence advocate instead for wholeschool and ecological approaches, that recognise the relationship between the young person, their behaviours and the contexts they spend time within, as outlined below (AVA, 2018; Rayment-McHugh et al., 2015).

\section{Whole-school approaches}

Rather than focussing on individual behaviours, prevention programmes delivered in schools offer opportunities to stop harmful behaviours developing through targeting the social contexts young people spend time. Activists, practitioners and researchers working in the field of gender-based violence advocate for whole-school approaches to preventing sexual harm (AVA, 2018). Whole-school approaches emphasise the need for prevention that includes multiple activities within schools and targets multiple stakeholders, including pupils, staff and parents.

The effectiveness and lasting impact of prevention programmes varies between approaches and methods. In their systematic review of school-based prevention programmes DeGue et al. (2014) highlighted a range elements that contribute to effective prevention approaches, including: being comprehensive and appropriately timed, using varied teaching methods, having a sufficient number of sessions, fostering positive relationships, being socioculturally relevant, use of well-trained staff and being theory driven. DeGue et al. (2014) demonstrate how programmes are unlikely to be successful when delivered in absence of changes to the socio-cultural contexts the harm arises within or when those environments may contradict the messages the programmes are trying to challenge. For example, if a programme aims to tackle intimate partner violence, but no interventions are made into the harmful social contexts perpetuating sexist discourses surrounding women and girls, they are unlikely to be successful. 
Evaluations of programmes aimed at preventing sexual violence in schools have consistently highlighted two effective programmes - safe dates and shifting boundaries, reviewed here. In the Centre for Disease Control's systematic review of primary prevention strategies for reducing sexual violence they identified three effective interventions - Safe Dates, Shifting Boundaries and Violence Against Women Act funding (1994) (DeGue et al., 2014). De Koker, Mathews, Zuch, Bastien, and Mason-Jones (2014) also identified safe dates and shifting boundaries as positive interventions into preventing the perpetration of adolescent intimate partner violence.

The Safe Dates Prevention Program for Dating Abuse aims to prevent sexual violence between young people by raising awareness of dating violence and its consequences (V. Foshee \& Langwick, 2004). This school-based programme targets young people through a ten-session program focussed on preventing intimate partner violence. Safe Dates uses a variety of methods including sessions on consequences of dating violence, a theatre production, discussions about gender roles, conflict management and healthy relationships. In doing so Safe Dates aims to challenge harmful norms and ideas about gender roles, create awareness of community resources and develop peer support. A randomised control trial four years after the programme was delivered in 14 schools found that students were significantly less likely to be victims of, or to perpetrate, IPV (V. A. Foshee et al., 1998).

Shifting Boundaries, is a dating violence prevention programme that also includes school-based education curriculum (Taylor, Mumford, \& Stein, 2015; Taylor, Stein, Mumford, \& Woods, 2013). In addition to the classroom education curriculum on sexual harassment and abuse, the programme uses a building-level intervention. Students create hotspot maps to identify unsafe areas within the school. Using this information, the students work with staff to use a variety of methods to increase safety in those areas including increased surveillance by staff, posters and temporary building restraining rules. Evaluations 
found that the building intervention, even when delivered alone, and particularly with the education programme, was successful at reducing sexual violence (Taylor et al., 2013). The success of this approach highlights the importance of dual approaches to reducing sexual violence, delivered at multiple levels, including targeting both young people and the environments they spend time.

\section{From whole school to contextual}

The approaches reviewed here - interventions with people displaying HSB, and whole-school prevention programmes- demonstrate the benefits of ecological approaches to sexual harm. Whether it is intervention with a person after an incident of sexual harm has occurred, or broader prevention work, research indicates the necessity for multiple, varied and holistic approaches that understand young people's ecology. However, research in the UK suggests, when HSB incidents occur in schools, predominantly an individual response is triggered (Carlene Firmin, 2017). The response may involve a referral of the young person or people to social care, with the subsequent intervention focussing on the individual young person. In some cases, schools may also draw upon whole-school preventive programmes, such as those outlined above. While whole-school approaches offer interventions into places, they vary from Contextual Safeguarding - the framework used within this paper - in a number of ways.

Whole school approaches recognise issues, such as sexual violence or bullying, as systemic and as such seek to target the entire school rather than individual young people ( $\mathrm{J}$. D. Smith, Schneider, Smith, \& Ananiadou, 2004). A whole-school approach:

Involves addressing the needs of learners, staff and the wider community, not only within the curriculum, but across the whole-school and learning environment. It implies collective and collaborative action in and by a school community to improve student learning, behaviour and wellbeing, and the conditions that support these. (UNESCO, 2018 para 1) 
Interventions are directed at a variety of levels - the school, classroom, home and individual ensuring the approach is reflected in a variety of ways, for example policies, school cultures, physical locations, by engaging parents, staff training, the curriculum and working with individual young people (Pearce, Cross, Monks, Waters, \& Falconer, 2011).

Contextual Safeguarding moves beyond whole-school approaches to consider the relationship between harmful behaviours, the school environment, neighbourhood and the child protection system beyond the school (C. Firmin, 2017). In addition to targeting interventions across the whole-school, contextual safeguarding considers how the school fits within broader safeguarding systems and multi-agency partnerships responsible for safeguarding children and young people for example, social care, the police, and health (Figure One).

Figure One: Individual, whole-school and contextual safeguarding assessments and interventions

Contextual Safeguarding extends the remit of traditional child protection services into locations such as schools, to consider ways to respond to HSB across schools and as part of a connected multi-agency response. That is, the factors within schools themselves - rather than solely individuals. Before presenting the findings from this project, the methodology and limitations of the study are reviewed.

\section{Methodology}

This study sought to consider multi-agency and school, responses and interventions into HSB happening in schools. The findings here come from a broader study that aimed to: 
- consider the range of systems, practices and cultures that enable or act as barriers to responding to HSB, both within schools and multi-agency partnerships

- develop tools, resources and frameworks that will support inspectorates, multi-agency partnerships and schools to assess their current response to HSB in schools.

The research team employed a theoretical approach and methodology that recognised the interplay between the different social spaces young people spend time in and the social conditions of harm in those places. Engaging a contextual safeguarding approach (C. Firmin, 2017) - one concerned with understanding and intervening in the wider social contexts young people spend time in beyond the home for the purpose of child protection - allowed us to consider how the social rules and practices within schools might enable or act as a barrier to safeguarding young people against HSB.

Researchers into sexual violence highlight the need for multi-agency responses (NICE, 2016). That is, approaches that include multiple practitioners, for example those including social care, education, health and the police. As the research sought to identify factors that support or hinder responses to HSB happening within school it was integral that the research was conducted in both schools and the multi-agency partnership. As such, the project comprised two research elements: the first within schools and the second, the wider local authority multi-agency partnership within which the schools were located.

\section{Research methods}

The research team used a mixed-methods approach, whereby the data collection methods used were mirrored in education providers (referred to as schools) and multi-agency partnerships. We carried out research in seven schools and four local authority multi-agency partnerships across England, United Kingdom. The research was carried out in secondary schools (aged 11-18) although all young people directly engaged were over 13 . Within each 
site, we established a local steering group to oversee the research and also a national steering group. Schools were selected to meet a diverse criteria. This included: $16-18$ provision $(n=2)$, further education colleges $(n=2)$, alternative provision for young people excluded from mainstream education $(n=2)$, special educational needs school $(n=1)$, split-site provision $(n=2)$, faith-based school $(n=1)$, majority-male $(n=3)$ and secular schools $(n=6)$. As different methods were completed in different sites the study does not aim to be representative but seeks to understand the factors that may support or prevent responses to HSB in the different schools. Table One below outlines the methods used:

Table One: Research methods

Complementary research methods were adapted for the two separate aspects of the research - in schools and multi-agency partnerships - but in the whole consisted of four approaches:

(1) Focus groups with young people, school staff and multi-agency practitioners to identify the types of harm and safety young people encounter and their perspectives on responses to HSB.

(2) Observations highlighted the relationship between students and staff and physical locations of safety/risk. In schools this involved break time, class transitions and observations within the classroom. Observations within the partnership included observations of multi-agency meetings relating to HSB.

(3) Reviews of case notes and documentation related to specific incidents of HSB outlined actions and responses taken to specific cases and in particular the relationship between schools and the multi-agency partnerships. Within schools, documentation was held in the form of behaviour incident logs that were reviewed to identify gaps in responses, trends in behaviour and specific language used to record harm. 
(4) Reviews of policies and procedures in schools and the partnerships provided detail of the response and interventions to different forms of harm in schools and the partnership.

\section{Focus group participants}

In total 33 focus groups were held and a total of 142 people were engaged in focus groups with young people, school staff and multi-agency practitioners. Table Two below outlines the gender breakdown of the groups:

Table Two: Focus group gender breakdown

The age of the young people engaged ranged from 13-21 with a mean age of 15. Participants for the focus groups were engaged through stakeholders in the school or multi-agency. For the multi-agency focus groups, the single point of contact in each site recruited participants from a range of professions including: police, social workers, youth workers, teachers and youth justice practitioners. Within schools the leadership team or designated safeguarding lead (DSL) recruited students and staff. Consent to participate was obtained beforehand by the parents of the young people and by young people themselves at the start of the focus group. While we suggested to the school staff that we were seeking to speak to a range of students, in terms of behaviour, attainment and communication skills, as the DSL recruited participants it is not possible to determine how diverse the sample was.

The research received ethical approval at both the faculty and university wide ethics boards. In addition, the head of each Local Safeguarding Children's Board granted consent for the research within the multi-agency partnership. We gained further consent from individual young people, parents and practitioners to take part in focus groups and Head Teachers provided consent for research within schools. 


\section{Analysis}

Research findings were transcribed and uploaded to Nvivo 11 and initially coded using an open coding approach. Key research themes were sense checked with the individual steering group in each site and the national research advisory group. We then employed second stage axial coding to identify themes from the data and established a list of enablers and barriers. Four overarching themes (referred to as levers) emerged: Structures and systems; identification; prevention, and; response and intervention. For each four levers a subset of codes were established separately for schools and multi-agency partnerships. In this article, I focus specifically on the lever response and intervention.

A number of limitations exist. Firstly, research evidence suggests that young people display HSB before entering into secondary education. Time and ethics constraints did not permit us to carry out research with this younger group. Furthermore, the research was carried out in four local authorities where the research team already had established relationships.

\section{Findings}

Four levers for addressing HSB in schools emerged from the findings. Under response and intervention we identified individual components: ten elements within schools and five elements within multi-agency partnerships. As opposed to behaviours or risk factors associated to individual people, these levers consider elements within schools more broadly, when responding to HSB. Figure Two below outlines all the identified components.

Figure Two: Response and intervention components

Taken together, these 15 components make up a whole-school and multi-agency response and intervention to address HSB in schools. In this article, nine individual components are presented with evidence from the research. As the findings indicated that effective HSB 
responses were not time-limited, the components are separated into initial response, ongoing support and future prevention.

\section{Initial response}

All participating schools indicated that violent or abusive incidents had either occurred in the school grounds or involving pupils from the school outside school. This often required schools to intervene immediately to respond to harm and protect young people. Here I present four components: referral, response to incident, partnership input and HSB resource.

\section{Referral}

In the UK, schools are legally obliged to refer incidents where a child has been harmed, or is at risk of harm, to children's social care and if necessary, the police (Department for Education, 2018a). However, the research indicated inconsistencies in how and when schools make referrals for HSB cases, despite having polices in place requiring them to do so. Observations and discussions with multi-agency partners highlighted a disparity between which schools refer cases and those that do not, regardless of the level of harm. In all of the multi-agency focus groups practitioners suggested schools were anxious about referring cases of HSB and in particular, having the skills and language required to discuss cases relating to sex and sexuality. Practitioners suggested this anxiety hindered the ability for practitioners to refer cases and in some cases limited school involvement once they had referred a case:

From my experience there's a lot of professional anxiety. When we get a referral and there's something in there, you ring up the teacher or the professional who's made the referral and start asking them about it and you can hear their anxiety, it's like they don't want to make safeguarding referrals, they just want to pass it on, they don't want to go into detail. There's a lot of professional anxiety about the topic. (Multi-agency focus group). 
For some staff it was felt their role in response and intervention ended at the point of referral internally to the school's the DSL:

It has been a case always, even when we do safeguarding training, they start off in September and say when the case is passed on to the designated person the chances of probably coming back to the teacher is really rare. They will deal with it, if it needs forwarding information they just do that. So our duty is just to pass it on to them. What they do with it is no longer our responsibility. (School staff focus group)

In many instances, referral pathways appeared to flow in one direction, whereby responses ended at the point of referral. However, school staff suggested when schools or individuals had good relationships with social care and contacts with whom to speak with, a partnership response was facilitated:

We've got something called [service name], it's a direct line into any kind of agency. [...] so you give them a call and say "I've got this problem, what is the best way to deal with it?" and usually they're pretty good, they'll say, "this is the line you should take" or "this is the action you should take". So I'd done that a few times and eventually it just got to the point where I was like, I need to just refer this in now, so it got referred into Social Care and within I think six hours, they were holding a meeting at the police station. (School staff focus group)

While some schools relied on multi-agency support to inform referrals, it was clear that some schools referred only at 'crisis-point'. And while all safeguarding procedures reviewed emphasised the need for, and outlined how to, refer cases many suggested that there was limited guidance on how respond to incidents beyond the referral process. This appeared to result in varied responses to HSB.

\section{Response to incidents}

Fundamental to response and intervention is how schools and partners respond to incidents themselves. Case reviews, behaviour logs and interviews indicated that responses varied 
significantly across schools and between cases. In some cases, interventions focussed on those directly involved, particularly the victim, and reflected a victim-blaming culture:

But again, I don't mean to be down on schools because they've got a lot on but part of the work that I do is advocating for the young people that I support and I support a lot of young people within school and a constant frustration for me and the young people is that the onus appears to be on the victim to manage their life within school. So, especially when the perpetrator is within the school as well, it's things like, "Well, you can go to the breakout room and you can do English there," or whatever, or, "Yes, we can do a managed move to another school," and there doesn't seem to be an awful lot going on for the perpetrator in terms of, you know, their noses being put out of joint, so to speak. Int: So, it's about moving and managing the victim rather than ...

Yeah and it is probably because it is easier. If you've got a victim and you've got six perpetrators within the same school, to manage the risk around that one individual is a lot easier than moving six and doing that, although it will revictimize the victim and make them feel that, "Well, I'm at wrong here and I'm not," but unfortunately, I think it's about having the people to be able to manage that risk around those people. (Multiagency focus group)

This practitioner's sentiments were evidenced in our own observations and the interventions employed in two of the three case reviews. For example, in one case involving the oral rape of a student by another pupil, the intervention developed focused predominantly on the victim and included mentoring, monitoring her social media use and lessons on consent. This was not the case in all schools. Some schools took steps to safeguard all young people, recognising the challenges and requirement to protect both victims and those instigating harm. Some suggested this was particularly important in HSB cases when those instigating harm often had intersecting vulnerabilities (Pitts, 2013):

It's educating rather than demonising, I think that's what we've got to remember, we've got to educate them, because they don't understand, rather than just punish them. If you've got a child that's been sexting and you exclude them for three days, they don't need to be excluded, they need to be taught why it's wrong, the law. (School staff focus group) 
Different staff members in schools may take responsibility for roles regarding safeguarding and therefore the management of responses. In all schools this was the DSL. As such, staff beyond the DSL were not always aware of interventions and responses to HSB when they occurred. However, all staff have a responsibility to safeguard young people and protect them. The findings suggest that school staff did not always respond appropriately to HSB incidents.

\begin{abstract}
We had a student who reported that she was sexually assaulted by another student, and I don't know if anything ever happened from that. I don't think she knows, she didn't feel like anything happened from that, and so she was really, it definitely upset her, because she was being really, one, her behaviour was quite bad, but I think it was because she was angry. [...]And I ended up having a conversation with her, just saying "you'll leave school and encounter situations like this outside of school, you've got to learn to like be resilient". That was sort of the only thing I could really say to her, just help her to understand that, it's not just, you know, like, yeah, which is kind of a sad conversation to have, but at the same time it's realistic I guess. (School staff focus group)
\end{abstract}

Failure to respond appropriately to incidents is contrary to statutory guidance, normalises harm and fails to protect young people. Young people indicated that, in cases where schools responded well, they were more likely to disclose further harm and to trust teachers. This echoes Aceves et al's (2010) findings where students observe how teachers respond to incidents, which affects the likelihood for students to seek help in the future. Our own findings demonstrated this:

It's happened to me before.

Int: That you've seen that [unwanted sexual touching by a group]?

It actually happened to me and I told a teacher about it, so it was, they sorted it out and then after they stopped but they tried it again three times, but they didn't do it again. Int: So given you've had that experience, you've still gone [and stood] down that end [indicating], that it would be good to tell [someone].So you would still recommend anybody else who had that happened, should tell? 
'Cause it's happened to me, if it was happening to someone else, I would stick by their side and I would actually help them out about it because I've experienced this before and I would tell them to tell the teacher about it because my head of year actually sorted it out for me and it didn't happen again, they tried it but it didn't work. (Young people's, focus group, girls)

Positive interventions by school staff, where young people felt supported, created a culture and situation where students felt more confident to approach staff for help in the future. In some cases, interventions by schools alone may be appropriate, but in many instances schools sought the advice and support of external agencies.

\section{Partnership inputs and HSB resource}

Essential to high-quality HSB responses is multi-agency input and support. This could include: skilled and knowledgeable inputs from specialist organisations, consistent messaging on HSB and providing extra support to schools (Lewis, 2018). While all sites had access to HSB provision, some suggested this was under-resourced. School staff and practitioners in all sites suggested there were significant challenges for schools responding to HSB and managing risk without specialist advice:

It can be challenging for schools to manage all the risk on their own. Often if they've referred cases it might be closed to social care, so once it comes to trial there's no longer any social worker involvement. And social work are unlikely to be building up cases again just because someone's received a conviction of rape. It doesn't automatically deem that there are other professionals involved like youth offending or harmful sexual behaviour lead. And then there's additional support. It's expensive for a school in terms of resources to in some instances place additional support and supervision in place for before school, after school, break times, lunch times in terms of staff members if they're making arrangements to provide additional support and supervision, if that is part of the support plan. (Multi-agency focus group)

Other practitioners noted the challenges of managing cases and responding to HSB incidents 
when the police decided upon no further action (NFA):

So essentially, young people are quite clear that there wouldn't necessarily be a punitive response so therefore they feel like it's not a problem. I think the other side where we've had issues is inconsistent response to rape allegations, when young people are getting NFA'd due to lack of evidence, we know there's loads of barriers to those cases proceeding through the criminal justice system but I feel like the police are seeing these young people and not necessarily referring into any services or sharing that information, so for these young people that may have perpetrated sexual violence, they're walking out of the station feeling like "I've got away with it" and can go through that cycle over and over again. (Multi-agency focus group)

Criminal processes constitute only one response to HSB. These cases require holistic and whole-school approaches that work with young people on a voluntary basis and respond to their needs even if cases are NFA'd. Schools are well placed to access and work with young people on a voluntary basis. But to do so, schools need to engage a variety of partners, be they from mental health, clinical services, social services, youth work or the police. In the majority of school-staff and practitioner focus groups it was suggested that cuts in funding to agencies impacted their ability to work with schools.

I just don't think education can handle it, they just don't have the resources and people and agencies, we all know we've got funding cuts and who is going to do that work? We've lost loads of workers, skilled workers in [Site name] because of funding cuts so even if they said, we're going to bring [sex education] back into PHSE, who's going to deliver that? (Multi-agency focus group)

The research evidenced variations in how schools respond to HSB and the resources available both within schools and the local partnership. While the majority of practitioners suggested this was the result of education cuts it was clear that in some sites, schools and agencies had prioritised HSB over other issues.

The findings indicate that following an incident, the central tenants of a good response 
to HSB are the referral to the multi-agency partnership, adequate resources to support schools and a response that works with all young people involved. Practitioners suggested this is not the case for all schools and that many dealt with issues 'in-house', did not respond, or did so in ways characterised by victim blaming. While the initial response was essential to responding to HSB, in some cases intervention ended at the point of referral. The findings demonstrate the importance of ongoing support, as outlined below.

\section{Ongoing support}

The findings echo research into adolescent harm that highlight the necessity of ongoing support for young people that have experienced or instigated sexual harm (Warrington, Ackerley, Beckett, \& Walker, 2017). From a contextual perspective, support needs to be integrated throughout the whole school and multi-agency partnership and cease when it is appropriate for all young people. Three components highlighted the importance and impact of ongoing support: wellbeing of students, staff motivation and peer support.

\section{Wellbeing of students}

The research indicated that schools could offer students continued monitoring and welfare. In some schools, pastoral teams provided ongoing support to students, which prioritised their mental health and could be accessed by all:

Int: If you were to tell a teacher or the support staff around this, what would their response be around that?

- Like that place there, they have a really good response, but I've never been in a situation where I've had to do that. But yeah, they're really, really good the ones there. They can talk to you, they try to actually get you help.

- The Student Support Centre's been really great for me.

- Yeah, the counsellors as well, the counsellors that I used to go to on a Wednesday, I'd always cry when I go there. I cried there twice. (Young people's focus group, boys) 
In other schools, students suggested counselling support would be beneficial. Students, school staff and practitioners could recount incidents where they felt student welfare had not been supported:

I spoke to the student and the student said it went nowhere. So, I said, "You need to get one of your family members to push this with the authorities, because a crime has been committed and you've been humiliated." The person who had done this to him was still in the college and no consequences whatsoever. So, he's free to go and do it again. I think some of that, the failings of that would have been one that whole situation was not taken seriously in that instance. I don't know if there were other instances where it was taken seriously, but I was very surprised that that wasn't taken further, the student had just sort of been left alone. No one in any position had given him any satisfaction. And the other student was still carrying on. (School staff focus group)

Varied responses to HSB incidents, especially where no changes were perceived to have taken place, not only adversely impacted students but also staff. This was particularly the case when staff did not feel supported and which in turn could be seen to reduce their motivation to respond.

\section{Staff motivation}

When there was no intervention into HSB, or there was a disparity in the responses between staff, staff suggested they felt unable to respond even if they wanted to because they did not feel supported. Previous responses to incidents and support by other staff meant teachers felt able to respond and students felt encouraged that staff would take them seriously:

Int: So, you say the school aren't very good, but there's clearly individual teachers and members of staff that are very good?

Yeah, like on a whole sometimes there's stuff that can be improved, but some individual teachers and definitely a lot of the counsellors they have gone above and beyond for some of us. (Young people's focus group, girls)

In other schools, lack of consistency in response resulted in situations where incidents were 
not responded to and staff felt unsupported:

If you just want to keep them working, get on with the lesson, you just end up ignoring a lot of things. My biggest concern is that I feel like we [female staff] try to very specifically address the nature of what's being said, whereas when a male staff member's there, it's more just like, they're just sort of passing it off as if it's just like saying fuck or shit or something, whereas it's like actually quite disturbing. And that's the issue I think. [...]But I guess it's just kind of, in that moment you either choose to reprimand that student and deal with the backlash and get even more verbally assaulted, or you choose to get the work done for that lesson and ignore that behaviour. (School staff focus group)

Staff motivation varied between schools. In some places staff felt motivated and able to respond whereas in others, while they understood the importance of acting, they felt the inconsistency in response by other staff undermined their ability to challenge harmful norms.

\section{Peer support}

In addition to formal support structures within the school itself, young people noted the importance of friendships with peers to offering support, advice and informal interventions. Many young people we spoke with suggested that a friend would be the first person they would go to if they had concerns. This might be for emotional support or by acting as a bystander and intervening in harmful incidents:

Well sometimes, because if it was your friend say that it was going round, then maybe you'd react differently to say if it was just some girl that you've talked to maybe once in a year. But if it's someone that's very close to you, then I think some people will grow up and speak [out against the harm]. If it's something different though, I don't know. (young people's focus group, girls)

In other incidences, young people suggested that they would rather speak to a friend for support than a teacher:

Int: Can I just ask, would it be different if it was your friend? 
- Yeah definitely, I would definitely talk about it.

- I wouldn't tell the teacher, I would actually ask her about it, and if not, I would go to the boy and confront him, like why would you do something like that?

- I mean it depends on who it is and what she does.

- She would be comfortable to go with him to have a conversation and say, "Why did you send it?"

- And also you might not want a teacher to know. Like I know that I'm not comfortable around a lot of teachers to tell them that sort of stuff. I don't really have that sort of relationship with any teachers. So, it would be very difficult. (young people's focus group, girls)

While this is sometimes the case, teachers and students suggested that peers could also intervene in ways that were abusive or violent. This was sometimes the case in instances where peers used violence or threats to get students to withdraw statements made to the police.

The other thing is violence, really quite, some nasty things going on and really unpleasant things, where girls have been attacked and when they've tried to do what we all hope that we would do, which is go to the authorities, then there is ganging up on the part of the school, not the authorities in the school but the getting all the mates together and having a real go and making that life so unpleasant that they don't feel either that they can take it forward or that (School staff focus group)

While formalised procedures outline the process from referral to multi-agency engagement, informal support networks offer opportunities to aid young people's ongoing welfare.

\section{Future prevention}

Practitioners suggested they felt interventions into harm were often reactive. Contextual responses to HSB require building responses that prevent future harm occurring. This requires an ongoing approach to HSB that recognises and integrates responses throughout the school and with partners. Three components highlighted this necessity: disseminating interventions, changing the physical environment and developing robust policy frameworks. 


\section{Dissemination of intervention}

The research indicated that incidents are either not responded to, or that students and staff are not aware of interventions. When students perceived no actions had taken place this reduced their confidence in the school. This also impacted staff, where it was felt that lack of communication between staff reduced their ability to ensure the ongoing wellbeing of students.

- I think one thing that I was quite surprised, because I haven't been here for that long and I'm fairly new as a teacher, was once we pass on things to other people, the person or child or whatever, even though that kid is still in my tutor group so no-one's briefed me on actually what's happened, I've sort of heard stuff about what's happened, and now I know what happened which is actually pretty big. But she's still in my tutor group and no-one's actually informed me or anything that I need to look out for, or how should I ... I don't know, I just don't feel informed, nothing's come back to me.

- That need to know circle is very small and it can be quite a detriment actually to the girl to provide enough support to the students.(School staff, focus group)

While it is important that confidentiality is maintained it is equally valuable that staff are kept informed where necessary. It was clear from behaviour logs that while some incidents were often responded to by the school, many students suggested they did not perceive there to be any intervention. In schools that engaged holistic responses, such as changing the curriculum, discussing issues in tutor groups or changing the physical environment, students suggested they were aware of the school not tolerating such behaviour which in turn informed their perception of HSB.

\section{Physical environment}

The majority of young people and staff engaged were able to name physical locations and places in schools where they felt harm occurred more than other places such as corridors, certain classrooms or parts of the playground: 
Are there particular locations in the school where ...?

- Well anywhere there's not really cameras or teachers, like the alley or near the toilets.

- And the tunnel. (Young people's focus group, girls)

While teachers acknowledged this, some suggested changing the physical environment was unfeasible. In two schools, changes had been made to the location of incidents:

Int: You were saying there should be more teachers around school, are there places around the school where some of these things happen more?

- Yes [all agree].

- Over there.

- It was cut off for a while okay, so there was a stage where they ... Now they've opened up the old reception, which is where we were, which is now called Student Support. But there used to be a lot of things there that would happen, like if a fight happened it would happen there.

- Or like boyfriends and girlfriends would like make out like they'd smoke (young people's focus group, girls)

Schools noted challenges in managing risk around schools, particularly when there is a lack of supervision by staff to do so. However, in some places, changes to the physical environment appeared to make young people feel safer in some places. This included preventing congregation in locations where issues such as sexual harassment had been a concern, changing the furniture in an area to promote students using the space, increasing CCTV or lighting or restricting the places that a student could access in cases where there were ongoing investigations into sexual assault.

\section{Policy framework}

Schools are increasingly required to outline in policy their response to HSB. Throughout the research there was a difference between schools in their response to HSB despite similar policy frameworks in place across schools. Schools with a strong policy framework and relevant and updated staff training supported staff to feel confident to respond to HSB: 
- No, I feel very confident to deal with that [sexual assault].

- I think we've got regular training to remind us of it.

Int: What sort of training do you have?

- We have face to face training from the DSL we've done online training.

- Updated policies sent through emails, "Please read this".

- There was some online training at the beginning of the year. (School staff focus group)

Yet in other places, teachers felt that the lack of consistent and clear policy meant that responses to HSB were inadequate:

But in terms of like what does that equal here, there'll be a discussion as to whether that kid should have a one to one session or be excluded or just not have any butter on their toast next day. Like there's not a fixed thing about what that equals, and so certainly there's not a clear message about it being inappropriate. That's my feeling. (School, staff focus group)

The majority of school staff suggested they would refer to policy guidance when determining how to respond to incidents. However, the research indicated that guidance often failed to provide the advice needed, especially in relation to peer-on-peer abuse. The findings demonstrate that the prevailing advice to schools - to make a referral to social care - is insufficient to meeting the needs of schools when managing HSB incidents. Additional advice on how to respond, ongoing support and an iterative approach to prevention are essential aspects that must embedded within policy and guidance.

\section{Discussion and conclusion}

Ecological approaches to HSB are informing assessments and interventions that appreciate the contexts young people spend time within, but do not necessarily intervene within them. This study extends this work by developing a contextual approach to intervention, highlighting the factors within schools themselves. Data analysis identified four levers, and within this, a range of components that support holistic response and interventions into HSB 
- ten within schools and five within multi-agency partnerships. These components indicate some of the enablers and barriers to responding to HSB in schools.

This article contributes to wider debates internationally advocating for improved safety within schools (Barter, 2009; C. Firmin, 2017; McKibbin, Humphreys, \& Hamilton, 2017). In this study, we found evidence of young people experiencing sexual harm in school settings, but that current policy guidance to schools is insufficient to support a contextual intervention into harm. The research found that violent and abusive HSB incidents, or behaviour that was escalating in nature, were responded to inconsistently between staff and across schools. In some cases, gendered approaches to HSB appeared to normalise forms of harm with some behaviours lacking any sufficient intervention. While the research was carried out in England, HSB in schools is an issue that schools are grappling with internationally. Findings from this paper would support education providers and external agencies internationally with a place to start from when considering their own responses to HSB from a contextual approach. There is ample opportunity to consider the findings applicability within international settings. For example, in international schools there is scope to for research and advice on how to respond to HSB in different cultural contexts.

Previous research has found that ineffective responses to HSB can position schools as hostile environments (Dobson \& Ringrose, 2016). While our own research shared similarities with these findings, we also found evidence of successful responses and interventions. This was particularly the case in schools where there were robust and clear policy frameworks that protected all young people from harm and where they offered consistent and ongoing support by dedicated pastoral teams. Young people related positive experiences where they had received support from members of staff and this appeared to influence who or how they would respond to future incidents. Taken together, these initial responses are crucial in 
setting a tone and expectation of how schools respond to HSB. Yet our findings suggest that initial, ongoing, and future support varied between schools and multi-agency partnerships. As did the prioritisation of schools and agencies funding prevention and intervention into HSB.

Following a HSB incident in schools, the predominant advice to schools in the UK is to refer cases of HSB to DSLs or social services. Our findings suggest that this advice is insufficient for supporting schools to attend to, and change, the factors within school settings themselves that may normalise harm and allow HSB to develop. While not an exhaustive list, the components outlined in this paper indicate factors that exist within schools - rather than young people themselves - that contextual interventions could seek to target. In presenting these findings I seek to challenge the individual focus of interventions into HSB and aim to extend the role of schools and multi-agency partners to respond and intervene within the contexts itself, creating safer schools for all young people.

\section{References}

Aceves, M. J., Hinshaw, S. P., Mendoza-Denton, R., \& Page-Gould, E. (2010). Seek help from teachers or fight back? Student perceptions of teachers' actions during conflicts and responses to peer victimization. Journal of Youth and Adolescence, 39(6), 658669.

AVA. (2018). The whole school approach model. Retrieved 1st March 2018, from https://avaproject.org.uk/ava-services-2/children-young-people/whole-schoolsapproach/

Barnes, A., Cross, D., Lester, L., Hearn, L., Epstein, M., \& Monks, H. (2012). The invisibility of covert bullying among students: Challenges for school intervention. Journal of Psychologists and Counsellors in Schools, 22(2), 206-226.

Barter, C. (2009). In the name of love: Partner abuse and violence in teenage relationships. British journal of social work, 39(2), 211-233.

Benton, C. J. (2014). Seven: The Profession Feminism Left Behind: Heterosexism in Schooling and the Teaching Profession. Wagadu: a Journal of Transnational Women's and Gender Studies, 12, 173. 
Borduin, C. M., \& Schaeffer, C. M. (2002). Multisystemic treatment of juvenile sexual offenders: A progress report. Journal of Psychology \& Human Sexuality, 13(3-4), $25-$ 42.

Borduin, C. M., Schaeffer, C. M., \& Heiblum, N. (2009). A randomized clinical trial of multisystemic therapy with juvenile sexual offenders: effects on youth social ecology and criminal activity. Journal of consulting and clinical psychology, 77(1), 26.

Caldwell, M. F. (2002). What we do not know about juvenile sexual reoffense risk. Child maltreatment, 7(4), 291-302.

Chaffin, M. (2008). Our minds are made up — don't confuse us with the facts: Commentary on policies concerning children with sexual behavior problems and juvenile sex offenders. Child maltreatment, 13(2), 110-121.

Cowie, H. (2011). Understanding why children and young people engage in bullying at school. Children Behaving Badly?: Peer Violence between Children and Young People, 33-45.

De Koker, P., Mathews, C., Zuch, M., Bastien, S., \& Mason-Jones, A. J. (2014). A systematic review of interventions for preventing adolescent intimate partner violence. Journal of Adolescent Health, 54(1), 3-13.

DeGue, S., Valle, L. A., Holt, M. K., Massetti, G. M., Matjasko, J. L., \& Tharp, A. T. (2014). A systematic review of primary prevention strategies for sexual violence perpetration. Aggression and Violent Behavior, 19(4), 346-362.

Department for Education. (2018a). Keeping Children Safe in Education staturotry guidance for schools and colleges. London: Crown Copyright.

Department for Education. (2018b). Sexual violence and sexual harassment between children in schools and colleges.

Dobson, A. S., \& Ringrose, J. (2016). Sext education: pedagogies of sex, gender and shame in the schoolyards of Tagged and Exposed. Sex Education, 16(1), 8-21.

Dopp, A. R., Borduin, C. M., Rothman, D. B., \& Letourneau, E. J. (2017). Evidence-based treatments for youths who engage in illegal sexual behaviors. Journal of Clinical Child \& Adolescent Psychology, 46(5), 631-645.

Duffy, J., Wareham, S., \& Walsh, M. (2004). Psychological consequences for high school students of having been sexually harassed. Sex Roles, 50(11), 811-821.

Espelage, D. L., \& Swearer, S. M. (2004). Introduction: A social-ecological framework of bullying among youth Bullying in American schools (pp. 23-34): routledge. 
Fineran, S. (2002). Sexual harassment between same-sex peers: Intersection of mental health, homophobia, and sexual violence in schools. Social work, 47(1), 65-74.

Firmin, C. (2017). Abuse between Young People: A Contextual Account. Oxon: Routledge.

Firmin, C. (2017). Contextual Risk, Individualised Responses: An Assessment of Safeguarding Responses to Nine Cases of Peer-on-Peer Abuse. Child Abuse Review.

Foshee, V., \& Langwick, S. A. (2004). Safe Dates: An adolescent dating abuse prevention curriculum: Hazelden Publishing.

Foshee, V. A., Bauman, K. E., Arriaga, X. B., Helms, R. W., Koch, G. G., \& Linder, G. F. (1998). An evaluation of Safe Dates, an adolescent dating violence prevention program. American journal of public health, 88(1), 45-50.

Girlguiding. (2017). Girls' attitudes survey.

Goldstein, S. E., Young, A., \& Boyd, C. (2008). Relational aggression at school:

Associations with school safety and social climate. Journal of Youth and Adolescence, $37(6), 641-654$.

Hackett, S. (2014). Children and young people with harmful sexual behaviours: Dartington.

Henggeler, S. W., Schoenwald, S. K., Borduin, C. M., Rowland, M. D., \& Cunningham, P. B. (2009). Multisystemic therapy for antisocial behavior in children and adolescents: Guilford Press.

House of Commons. (2016). Sexual harassment and sexual violence in schools. London.

Jones, N., Moore, K., Villar-Marquez, E., \& Broadbent, E. (2008). Painful lessons: The politics of preventing sexual violence and bullying at school. London: Overseas Development Institute (ODI).

Letourneau, E. J., \& Borduin, C. M. (2008). The effective treatment of juveniles who sexually offend: An ethical imperative. Ethics \& behavior, 18(2-3), 286-306.

Letourneau, E. J., Henggeler, S. W., Borduin, C. M., Schewe, P. A., McCart, M. R., Chapman, J. E., \& Saldana, L. (2009). Multisystemic therapy for juvenile sexual offenders: 1-year results from a randomized effectiveness trial. Journal of Family Psychology, 23(1), 89.

Lewis, R. (2018). Literature review on children and young people demonstrating technologyassisted harmful sexual behavior. Aggression and Violent Behavior.

Masson, H., \& Hackett, S. (2003). A decade on from the NCH Report (1992): Adolescent sexual aggression policy, practice and service delivery across the UK and Republic of Ireland. Journal of Sexual Aggression, 9(2), 109-124. 
McGrath, R. J., Cumming, G. F., Burchard, B. L., Zeoli, S., \& Ellerby, L. (2009). Current practices and emerging trends in sexual abuser management. The Safer Society, 24.

McKibbin, G., Humphreys, C., \& Hamilton, B. (2017). "Talking about child sexual abuse would have helped me": Young people who sexually abused reflect on preventing harmful sexual behavior. Child Abuse \& Neglect, 70, 210-221.

Nelson, H. J., Burns, S. K., Kendall, G. E., \& Schonert-Reichl, K. A. (2017). The factors that influence and protect against power imbalance in covert bullying among preadolescent children at school: a thematic analysis. The Journal of School Nursing, 1059840517748417.

NICE. (2016). Harmful sexual behaviour among children and young people.

Pearce, N., Cross, D., Monks, H., Waters, S., \& Falconer, S. (2011). Current evidence of best practice in whole-school bullying intervention and its potential to inform cyberbullying interventions. Journal of Psychologists and Counsellors in Schools, 21(1), 1-21.

Pitts, J. (2013). Drifting into trouble: Sexual exploitation and gang affilitation. In M. Melrose \& J. Pearce (Eds.), Critical Perspectives on Child Sexual Exploitation and Related Trafficking (pp. 23-37). Hampshire: Palgrave Macmillan.

Pratt, R. (2013). A community treatment model for adolescents who sexually harm: Diverting youth from criminal justice to therapeutic responses. International journal of behavioral consultation and therapy, 8(3-4), 37.

Rayment-McHugh, S. N., Smallbone, S., \& Tilley, N. (2015). Endemic sexual violence and abuse: contexts and dispositions. International Journal for Crime, Justice and Social Democracy, 4(2), 111-124.

Ronis, S. T., \& Borduin, C. M. (2013). Antisocial behavior trajectories of adolescents and emerging adults with histories of sexual aggression. Psychology of Violence, 3(4), 367.

Scott, J., \& Telford, P. (2006). Similarities and Differences in Working with Girls and Boys Who Display Sexually Harmful Behaviour. Children and Young People Who Sexually Abuse Others, Second edition. Routledge.

Smallbone, S., Rayment-Mchugh, S., \& Smith, D. (2013). Youth sexual offending: Context, good-enough lives, and engaging with a wider prevention agenda. International journal of behavioral consultation and therapy, 8(3-4), 49.

Smith, C., Allardyce, S., Hackett, S., Bradbury-Jones, C., Lazenbatt, A., \& Taylor, J. (2014). Practice and policy in the UK with children and young people who display harmful 
sexual behaviours: an analysis and critical review. Journal of Sexual Aggression, 20(3), 267-280.

Smith, J. D., Schneider, B. H., Smith, P. K., \& Ananiadou, K. (2004). The effectiveness of whole-school antibullying programs: A synthesis of evaluation research. School Psychology Review, 33(4), 547.

Swain, J. (2006). Reflections on patterns of masculinity in school settings. Men and Masculinities, 8(3), 331-349.

Taylor, B. G., Mumford, E. A., \& Stein, N. D. (2015). Effectiveness of "Shifting Boundaries" Teen dating violence prevention program for subgroups of middle school students. Journal of Adolescent Health, 56(2), S20-S26.

Taylor, B. G., Stein, N. D., Mumford, E. A., \& Woods, D. (2013). Shifting Boundaries: an experimental evaluation of a dating violence prevention program in middle schools. Prevention science, 14(1), 64-76.

The Good Lives Model. (2018). Information. Retrieved 11 January 2018, from https:/www.goodlivesmodel.com/information\#General

Turner, H. A., Finkelhor, D., Hamby, S. L., Shattuck, A., \& Ormrod, R. K. (2011). Specifying type and location of peer victimization in a national sample of children and youth. Journal of Youth and Adolescence, 40(8), 1052-1067.

UNESCO. (2018). Whole school approaches. Retrieved 18 May 2018, from http://www.ibe.unesco.org/en/glossary-curriculum-terminology/w/whole-schoolapproach

Ward, T., \& Brown, M. (2004). The good lives model and conceptual issues in offender rehabilitation. Psychology, Crime \& Law, 10(3), 243-257.

Ward, T., Vess, J., Collie, R. M., \& Gannon, T. A. (2006). Risk management or goods promotion: The relationship between approach and avoidance goals in treatment for sex offenders. Aggression and Violent Behavior, 11(4), 378-393. doi: https://doi.org/10.1016/j.avb.2006.01.001

Warrington, C., Ackerley, E., Beckett, H., \& Walker, M. (2017). Making noise: children's voices for positive change after sexual abuse: University of Bedfordshire/Office of Children's Commissioner.

Young, A. M., Grey, M., \& Boyd, C. J. (2009). Adolescents' experiences of sexual assault by peers: Prevalence and nature of victimization occurring within and outside of school. Journal of Youth and Adolescence, 38(8), 1072-1083. 
Tables and Figures
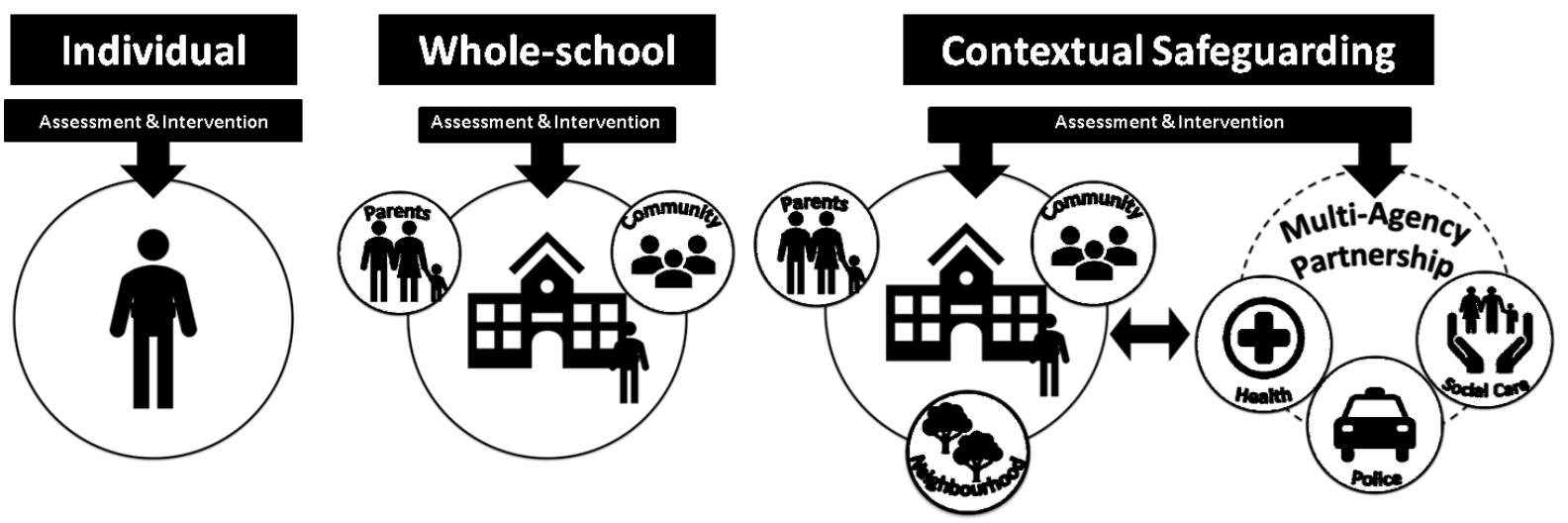

Figure One: Individual, whole-school and contextual safeguarding assessments and interventions

\begin{tabular}{|c|c|}
\hline Schools & Multi-agency partnerships \\
\hline $\begin{array}{l}\text { - } 17 \text { focus groups with young people } \\
\text { - } 12 \text { focus groups with school staff } \\
\text { - } 8 \text { observations in schools } \\
\text { - } 8 \text { reviews of behaviour incident logs } \\
\text { within schools } \\
\text { - } \text { Review of policies and procedures }\end{array}$ & $\begin{array}{l}\text { - } 4 \text { focus groups with multi-agency } \\
\text { practitioners } \\
\text { - } 16 \text { observations of multi-agency } \\
\text { meetings relating to HSB } \\
\text { - } 3 \text { case reviews of incidents of HSB } \\
\text { - } \quad \text { Review of policies and procedures }\end{array}$ \\
\hline
\end{tabular}

Table One: Research methods

\begin{tabular}{|l|l|l|l|l|}
\hline & $\begin{array}{l}\text { Number of focus } \\
\text { groups }\end{array}$ & $\begin{array}{l}\text { Total } \\
\text { participants per } \\
\text { group- female }\end{array}$ & $\begin{array}{l}\text { Total } \\
\text { participants per } \\
\text { group- male }\end{array}$ & $\begin{array}{l}\text { Total number of } \\
\text { participants }\end{array}$ \\
\hline Young people & 17 & 26 & 33 & 59 \\
\hline School staff & 12 & 36 & 22 & 58 \\
\hline Multi-agency & 4 & 19 & 6 & 25 \\
\hline Total & 33 & 81 & 61 & 142 \\
\hline
\end{tabular}

Table Two: Focus group gender breakdown 


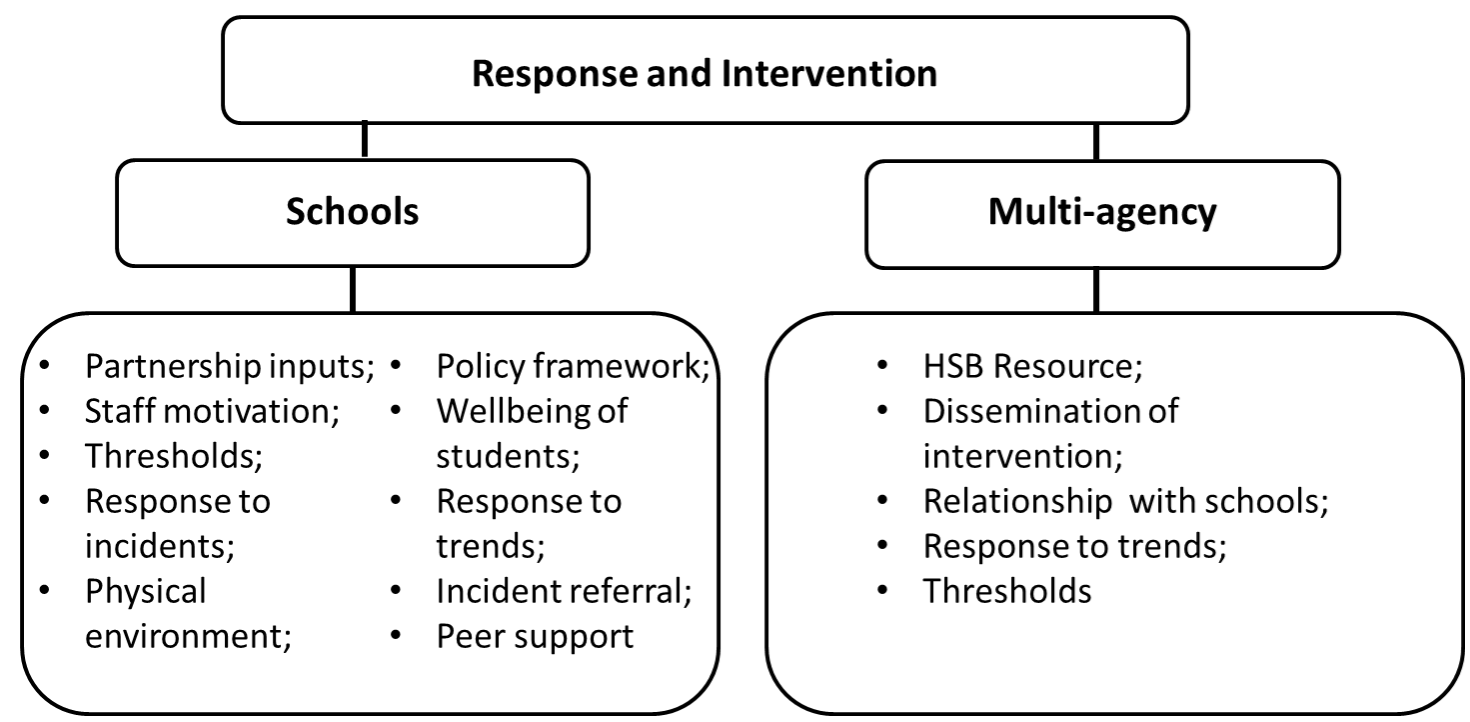

Figure Two: Response and intervention components 